\title{
TINJAUAN SEMIOTIKA KOMUNIKASI VISUAL IKLAN CALEG SUPERMAN (Studi Kasus Iklan Politik Caleg Superman Pada Website Caleg Superman Tahun 2014)
}

\author{
Edythia Indrasswary Nabella \\ Program Studi Desain Komunikasi Visual \\ FSR ISI Yogyakarta
}

\begin{abstract}
Politic publicity is a form of promotion of individual or party by creating politic image designed to persuasive people's perspective (public) to choose him on election days. Egy Massadiah is one of legislative candidates that campaign through unique ways by parodying himself as a Superman in a campaign props in website www.egymassadiah.info. This observation has purpose to analyze message in visual sign politic publicity legislative candidate Superman by using semiotic theory that belongs to Roland Barthes. This qualitative observation method using semiotic analysis approach connotation signification Roland Barthes to analyze message that contain in visual sign politic publicity legislative candidates Superman.

The conclusion from the result of the observation is connotation that grow become a myth in society, that choosing a leader candidates is not enough if it only based by the appearance or by look, also for the leader candidate that always distort the reality, blowing up things itself will create identity crisis from the leader candidate. Because something that exaggerated at first, only leave disappointment at the end and what only left is fiction.
\end{abstract}

Keywords: Political Publicity, Semiotic, Visual Communication Design, Roland Barthes

Relevance to Visual Communication Design Practice: This paper can be use as a concept paradigm when creating connotation meaning of an objects.

\section{A. LATAR BELAKANG}

Periklanan mendapat sorotan tajam semenjak aspek informasi menjadi bagian penting dalam bisnis, kegiatan periklanan dianggap mampu mempengaruhi kecenderungan masyarakat dalam mengkonsumsi suatu produk atau jasa yang ditawarkan. Ada tiga istilah yang umum dipakai di Indonesia untuk menyebut advertising, yaitu: reklame, advertensi, dan iklan. Reklame berasal dari bahasa Belanda, reclame dan bahasa Perancis reclamare. Advertensi berasal dari bahasa Belanda advertentie yang juga mengacu pada bahasa Inggris, advertising. Iklan merupakan bentuk komunikasi massa, komunikasi yang dilakukan oleh pengiklan (advertiser) untuk mengkomunikasikan sesuatu kepada konsumen (decoder) melalui media (channel). Iklan adalah semua bentuk aktivitas yang merupakan bentuk komunikasi untuk menghadirkan dan mempromosikan ide, barang, jasa, secara nonpersonal yang dibayar oleh sponsor tertentu. Tujuan iklan untuk membujuk atau menggiring orang yang akan mengambil tindakan yang menguntungkan bagi pihak pembuat iklan (Durianto, Sugianto, Hendrawan, 2003).

Dalam seratus tahun terakhir, iklan telah berkembang dari sekedar pengumuman pelayanan toko menjadi organisasi bisnis 
raksasa para kapitalis. Menguasai seluruh lapisan komunikasi di mediamassa cetak dan elektronik sehingga keduanya tidak dapat hidup tanpa iklan. Iklan juga menjadi alat pengaruh di wilayah politik, merambat dan mendikte nilai-nilai yang dianut masyarakat, yang pada akhirnya iklan mengambil alih seluruh sistem komunikasi masyarakat.

Secara umum, iklan terbagi menjadi Iklan komersial, yang disebut pula iklan bisnis, bertujuan untuk mendapatkan keuntungan ekonomi dengan menewarkan barang atau jasa. Lalu Iklan Layanan Masyarakat (ILM) yang merupakan bagian dari kampanye social marketing yang bertujuan menjual gagasan atau ide untuk kepentingan atau pelayanan masyarakat. Biasanya pesan Iklan Layanan Masyarakat berupa ajakan, pernyataan atau himbauan kepada masyarakat untuk melakukan atau tidak melakukakan suatu tindakan demi kepentingan umum atau merubah perilaku dari yang tidak baik menjadi perilaku yang baik.

Iklan politik merupakan semua bentuk aktifitas untuk menghadirkan dan mempromosikan individu maupun partai, secara nonpersonal melalui media yang dibayar oleh sponsor tertentu, berisikan muatan-muatan politik, seperti berisikan profil pribadi tokoh elit partai, yang nantinya akan membangun minat pilih masyarakat untuk memberikan hak suaranya kepada calon yang lebih dikenal masyarakat melalui iklan yang sering mereka lihat (Arif Mustofa, 2009). Menurut Sumbo Tinarbuko, Iklan politik ialah upaya menyampaikan pesan verbal visual perikehidupan politik yang didesain secara komunikatif. Iklan politik disampaikan oleh individu atau sekelompok orang yang tergabung dalam parpol, atau dibuat oleh seseorang yang memasuki jagad politik secara mandiri dan independen (Sumbo Tinarbuko, 2013).

Menjelang Pemilu 9 April 2014 lalu, iklan-iklan calon anggota legislatif menjamur di sana sini, tapi sayangnya banyak iklan yang malah menuai hujatan, bukannya menarik simpati. Hal itu disebabkan karena iklan-iklan caleg dipasang sembarangan dan sangat mengotori wajah kota. Public space yang seharusnya menjadi penyegar mata justru dikotori dengan gambar-gambar caleg yang mengumbar janji. Pohon, tiang, bahkan jembatan menjadi objek penempelan gambar kampanye caleg. Menjamurnya sampah visual iklan politik yang terpasang secara ngawur, cenderung menurunkan citra, kewibawaan, reputasi, dan nama baik parpol dan bakal caleg itu sendiri. Padahal dalihnya, niatan menjagokan diri sebagai bakal caleg, dilandasi doa suci untuk membangun Indonesia menjadi lebih baik. Bercita-cita mewujudkan janji kemerdekaan lewat representasi tata pemerintahan yang lebih baik. Dampak dari sampah visual ini menyebabkan iklan politik yang diposisikan sebagai ajang menyampaikan informasi dan mempromosikan keberadaan bakal caleg terperosok menjadi media miskomunikasi visual. Ujung dari semuanya itu ialah matinya iklan politik secara tidak terhormat (Sumbo Tinarbuko, 2013).

Adanya sampah visual yang mulai banyak diperdebatkan masyarakat ini juga menjadi perhatian Egy Massadiah, yang tidak lain adalah seorang calon legislatif DPR RI dari Partai Golkar untuk daerah pemilihan Jakarta Selatan, Jakarta Pusat dan luar negeri. Kegundahan Egy terhadap ulah para caleg itu 
diwujudkan dengan tidak menjadi bagian dari caleg yang menempel gambar-gambar di public space.

Egy lahir di Bugis Sengkang, Sulawesi Selatan pada tahun 1971, Egy yang juga aktor Teater Mandiri besutan Putu Wijaya memilih kampanye kreatif agar bisa dinikmati setiap orang tanpa mengganggu pemandangan. Egy memilih membuat website yang menarik orang untuk mengetahui siapa dirinya, dia juga aktif dalam kampanye di media sosial seperti twitter dan facebook. Uniknya semua kampanye Egy di internet bernuansa tokoh superhero terkenal yaitu Superman.

Egy menampilkan dirinya sebagai sesuatu yang berbeda, menggambarkan dirinya sebagai seorang superhero, yaitu Superman. Visualisasi alat peraga kampanye (APK) caleg Superman milik Egy seperti mengikuti perkembangan jaman, sehingga alat peraga kampanye miliknya sempat menarik masyarakat kalangan muda, hingga Ia mendapat julukan sebagai caleg gaul karena selain cara kampanye nya berbeda, gambar yang dipakai untuk kampanye juga keren dan unik. Hal inilah yang menarik perhatian untuk diteliti, mengapa sebenarnya Egy menggunakan unsur parodi dengan menggambarkan dirinya sebagai seorang superhero superman, dan apa makna atau maksud yang terkandung dalam gambar kampanye caleg superman Egy dalam poster yang tercantum di website www.egymassadiah.info. Alat peraga kampanye caleg superman Egy Massadiah ini akan dianalisis dengan menggunakan teori semiotika Roland Barthes.

Penelitian ini bertujuan untuk mengetahui sistem tanda yang melingkupi pemaknaan dan bahasa visual, serta makna semiotika yang terkandung dalam visualisasi iklan caleg superman. Agar pembaca bisa mengetahui makna yang terkandung dalam tanda pada visualisasi iklan politik tersebut. Dengan penelitian ini, penulis juga berharap akan menambah wawasan tentang ilmu pemaknaan yang terkandung dalam teori semiotka, baik untuk penulis sendiri maupun untuk pembaca.

\section{B. RUMUSAN MASALAH DAN TUJUAN PENELITIAN}

\section{a. Rumusan Masalah:}

Makna apakah yang terkandung dalam visualisasi iklan caleg Superman pada website www.egymassadiah.info menurut pandangan ilmu semiotika Roland Barthes?

\section{b. Tujuan Penelitian:}

1. Menginterpretasikan tanda - tanda yang terkandung di balik visual iklan Egy Massadiah sebagai caleg Superman.

2. Mencari makna dari tanda di balik visual iklan politik Egy Massadiah sebagai caleg Superman.

\section{TEORI DAN METODE}

a. Teori:

1. Iklan Politik

Iklan Politik Iklan merupakan bentuk komunikasi massa, komunikasi yang dilakukan oleh pengiklan (advertiser) untuk mengomunikasikan sesuatu kepada konsumen (decoder) melalui channel (media). Dan iklan digunakan untuk mencapai sasaran jangka panjang dan jangka pendek (Santosa, 2009:1). Dari pengertian iklan menurut Sigit Santosa dalam buku "Creative Advertising" dan jika padukan dengan politik, maka iklan politik adalah taktik penyampaian pesan, baik 
pesan verbal (visi dan misi) maupun pesan verbal (foto diri) melalui media yang didesain sedemikian rupa secara komunikatif guna menarik hati masyarakat atau audience. Iklan politik biasanya disampaikan oleh kelompok orang yang tergabung dan ada sangkut pautnya dengan partai politik tertentu.

\section{Semiotika Roland Barthes}

Tinjauan semiotika merupakan suatu kegiatan pengumpulan data, mengelola dan menganalisa data yang berupa tanda-tanda untuk ditafsirkan, sehingga menemukan makna yang terkandung dalam tanda tersebut. Semiotika akan menjadi acuan teori dalam penelitian ini

\section{Teori Parodi}

Parodi sebagai sebuah proses komunikasi yang terkandung dalam visual iklan politik Caleg Superman menjadi sebuah penerapan mengkomunikasikan pesan kepada khalayak.

\section{b. Metode Penelitian}

Penelitian ini menggunakan metode kualitatif dimaksudkan untuk memahami makna yang terkandung dalam tanda tanda visual dalam subjek penelitian. Mengidentifikasi objek yang diteliti untuk dipaparkan, dianalisis, dan kemudian ditafsirkan maknanya. Metode penelitian kualitatif adalah penelitian yang digunakan untuk meneliti pada kondisi objek alamiah dimana peneliti merupakan instrumen kunci

\section{PEMBAHASAN HASIL PENELITIAN}

Berdasarkan penelitian yang dilakukan terhadap iklan politik Caleg Superman dengan pendekatan teori Semiotika milik Roland Barthes dengan cara mengidentifikasi, deskripsi dan menginterpretasikan objek penelitian, maka diperoleh hasil penelitian sebagai berikut:

\section{Pesan Verbal 1}

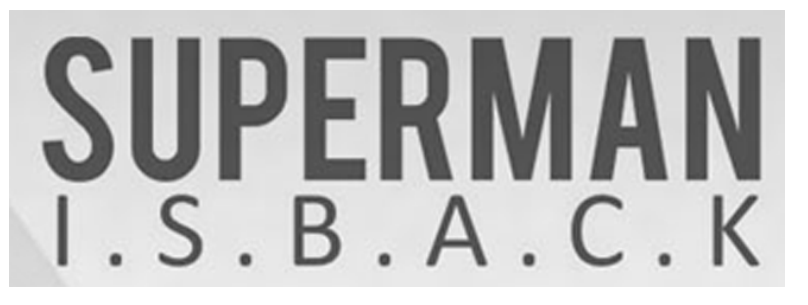

Gambar 1 Ringkasan Pemaknaan Pesan Verbal 1 Sumber : Edythia I N

Dari penjabaran petanda dan penanda yang telah dijabarkan dalam lampiran penelitian, penulis memaknai sebagai berikut: Telah bangkit kembali, sebuah cahaya yang sudah lama mati, cahaya itu adalah seorang bintang atau idola yaitu sang Superman. Superman yang dimaksud dalam makna ini adalah Egy Massadiah, makna yang mengandung sebuah plesetan atau parody tentang seorang superhero yang perannya digantikan oleh seorang calon legislatif.

\section{Pesan Verbal 2}

\section{BANG EGY MENUJUKESENAYAN PAKESEPATU GAKPAKEKAOSKAKI}

Gambar 2 Ringkasan Pemaknaan Pesan Verbal 2 Sumber : Edythia I N

Dari penjabaran petanda dan penanda yang telah dijabarkan dalam lampiran penelitian, penulis memaknai sebagai berikut: 
Egy menginginkan dirinya menjadi seorang anggota dewan, agar keinginannya itu tercapai maka Egy mencalonkan dirinya sebagai Calon Legislatif. Egy mempunyai cara yang berbeda (difference) untuk berkampanye, guna memperkenalkan dirinya kepada masyarakat sebagai seorang Calon Lesgislatif. Cara berkampanye Egy yang berbeda adalah dengan berkampanye sehat, agar tidak merusak wajah kota, yaitu dengan cara berkampanye online.

\section{Pesan verbal 3}

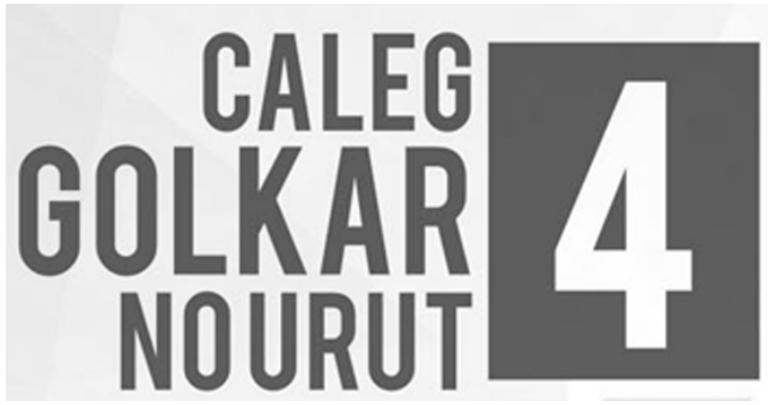

Gambar 3 Ringkasan Pemaknaan Pesan Verbal 3 Sumber : Edythia I N

Dari penjabaran petanda dan penanda yang telah dijabarkan dalam lampiran penelitian, penulis memaknai sebagai berikut: Keinginan Egy yang kuat untuk menjadi anggota legislatif, sempat diselimuti rasa keragu-raguan. Padahal ketidak yakinan atau keragu-raguan itu sendiri yang nanti bisa membuatnya gagal.
4. Pesan verbal 4

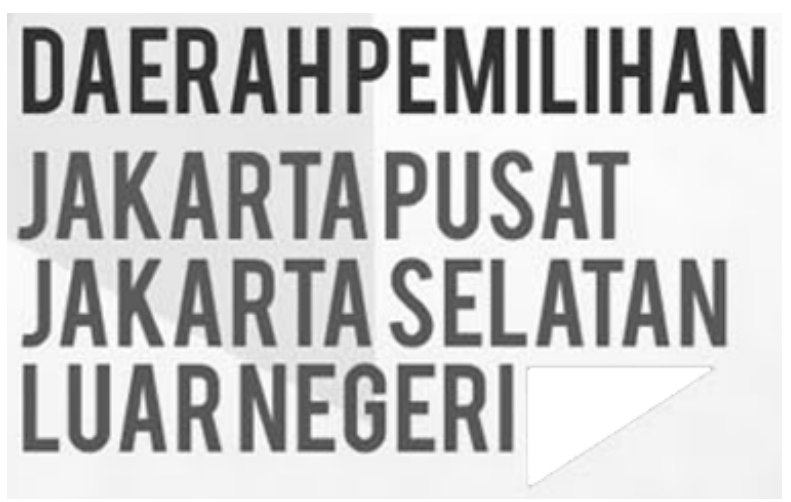

Gambar 4 Ringkasan Pemaknaan Pesan Verbal 4 Sumber : Edythia I N

Dari penjabaran petanda dan penanda yang telah dijabarkan dalam lampiran penelitian, penulis memaknai sebagai berikut: Meskipun diselimuti rasa ragu-ragu untuk menjadi seorang anggota dewan, Egy juga berkeyakinan bahwa Ia mempunyai hak untuk menang. Egy mempunyai harapan besar untuk beruntung dalam perolehan jumlah surat suara dalam 3 tempat daerah pemilihannya.

\section{Pesan Verbal 5}

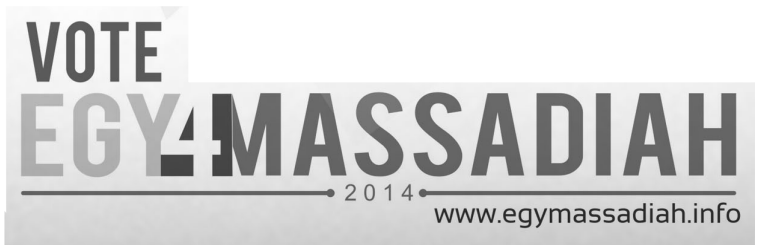

Gambar 5 Ringkasan Pemaknaan Pesan Verbal 5 Sumber : Edythia I N

Dari penjabaran petanda dan penanda yang telah dijabarkan dalam lampiran penelitian, penulis memaknai sebagai berikut: Egy mengajak masyarakat untuk memilihnya, agar masyarakat mau memilihnya, Egy melakukan pencitraan sebagai seorang yang 
baik dan rendah hati agar terlihat indah dan menarik dimata masyarakat. Dalam tanda Gestalt dalam pesan verbal diatas, menunjukkan bahwa Egy memaksakan dirinya untuk menjadi orang nor satu, namun Egy tidak punya cukup massa untuk mengangkat namanya menjadi anggota dewan, pemotongan huruf $M$ dimaknai sebagai Egy memotong massa nya sendiri, memotong jumlah massa nya untuk diberikan kepada partai lain, PDI (merah) dan PKS (merah putih), yang malah mematikan atau menjatuhkan Egy dalam pemilu.

\section{Pesan Visual 1}

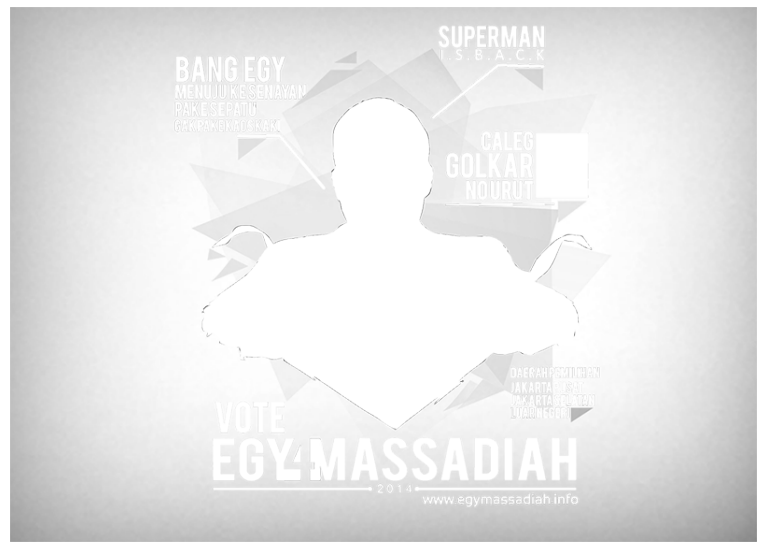

Gambar 6 Ringkasan Pemaknaan Pesan Visual 1 Sumber : Edythia I N

Dari penjabaran petanda dan penanda yang telah dijabarkan dalam lampiran penelitian, penulis memaknai sebagai berikut: Egy muncul untuk menarik perhatian masyarakat, juga untuk mengiklankan dirinya bahwa Ia adalah Calon Legislatif dari partai Golkar yang akan muncul nanti sebagai salah satu kandidat Caleg pada pemilu 2014. Seperti tanda-tanda sebelumnya, warna abu-abu yang dominan ada pada semua tanda mengandung makna bahwa Ia sebenarnya masih ragu-ragu. Bisa tidak dirinya menjadi Anggota Legislatif, atau nantinya Ia akan kembali menjadi rakyat biasa. Bersifat kabur, menggambang, atau bahkan plin-plan. Ketidak yakinan pada dirinya sendiri. Tanda dalam pesan di atas mempunyai makna bahwa jika masyarakat bersatu untuk memberikan dukungan pada Egy, maka partai Golkar akan semakin tangguh atau kokoh. Tangguh dalam membantu pembangunan untuk rakyat.

\section{Pesan Visual 2}

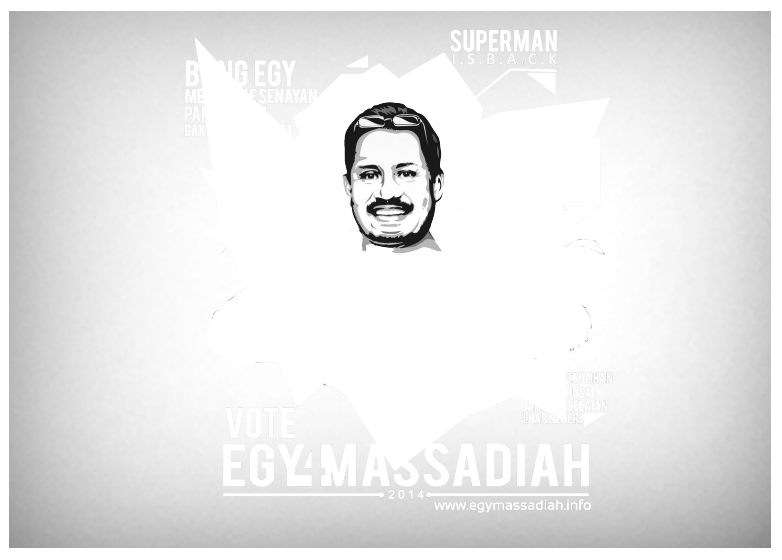

Gambar 7 Ringkasan Pemaknaan Pesan Verbal 1 Sumber : Edythia I N

Dari penjabaran petanda dan penanda yang telah dijabarkan dalam lampiran penelitian, penulis memaknai sebagai berikut: Pandai dalam mencitrakan dirinya, karena juga latar belakang Egy yang berasal dari teater, maka berpura-pura atau acting sudah merupakan bakat yang dimilikinya. Sehingga dalam kampanye pencalonan Caleg ini, Ia tidak kesulitan untuk mencitrakan diri. Egy Massadiah mencitrakan dirinya sebagai seorang caleg yang berwibawa dan bersih, patuh pada aturan-aturan yang ada dalam masyarakat. 
8. Pesan Visual 3

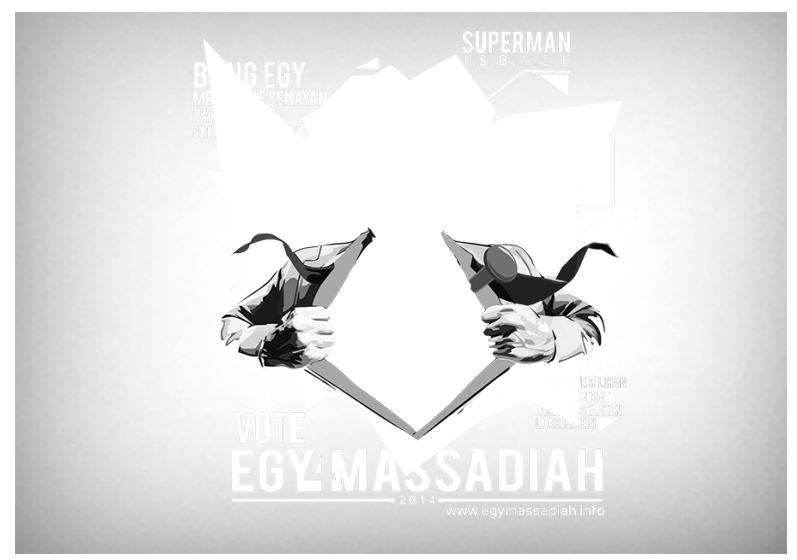

Gambar 8 Ringkasan Pemaknaan Pesan Verbal 1 Sumber : Edythia I N

Dari penjabaran petanda dan penanda yang telah dijabarkan dalam lampiran penelitian, penulis memaknai sebagai berikut: Egy siap menang karena Ia merasa mempunyai modal untuk menjadi seorang anggota legislatif. Ia tetap memaksakan dirinya untuk menjadi seorang caleg dengan pencitraan sebagai caleg baik dan rendah hati dimata masyarakat.

\section{Pesan Visual 4}

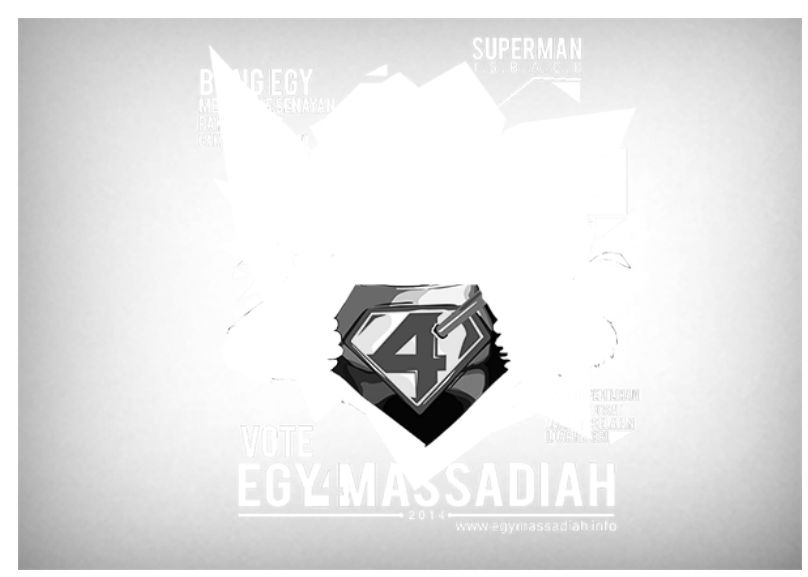

Gambar 9 Ringkasan Pemaknaan Pesan Visual 4 Sumber : Edythia I N

Dari penjabaran petanda dan penanda yang telah dijabarkan dalam lampiran penelitian, penulis memaknai sebagai berikut:
Egy merasa bangga jika dirinya bertemu dengan masyarakat secara langsung, Egy mengganggap dirinya adalah seorang pahlawan atau penyelamat.

\section{Pesan Visual 5}

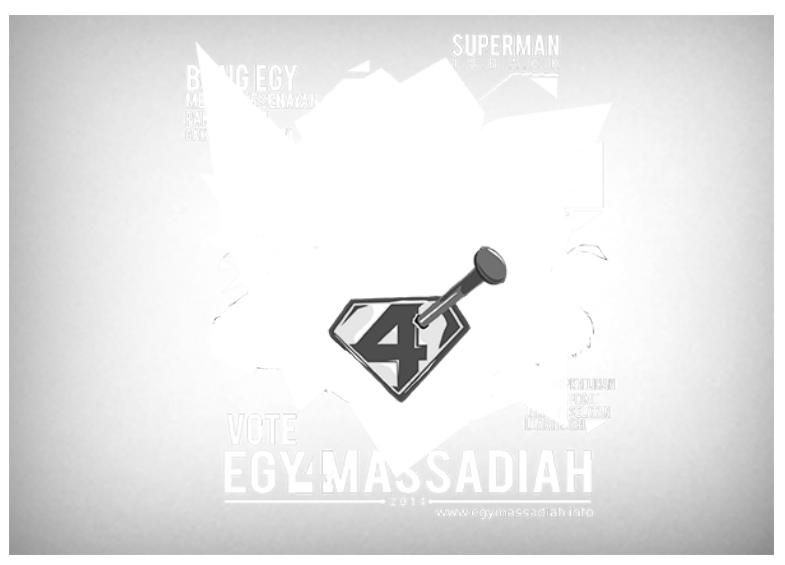

Gambar 10 Ringkasan Pemaknaan Pesan Visual 4 Sumber : Edythia I N

Dari penjabaran petanda dan penanda yang telah dijabarkan dalam lampiran penelitian, penulis memaknai sebagai berikut: Egy gagal menjadi anggota legislatif, massa yang mendukungnya kalah banyak dengan caleg lain yang maju terpilih sebagai pemenang. Egy berduka karena kalah.

\section{E. KESIMPULAN}

Setelah dilakukan analisis semiotik terhadap iklan politik Caleg Superman tahun 2014 pada website www.egymassadiah.info, dengan menggunakan teori Semiotika Roland Barthes, teori Posmodernisme Linda Hutcheon, dan teori Desain Komunikasi Visual, maka dapat ditarik beberapa kesimpulan dalam kajian ini antara lain :

1. Makna konotasi yang muncul dalam Iklan Politik Caleg Superman cukup beragam. Makna konotasi tersebut antara lain : 1) 
image Calon Lesgislatif, 2)Penilaian masyarakat terhadap Calon Legislatif.

2. Dalam kerangka Barthes, konotasi identik dengan operasi ideologi atau disebutnya sebagai mitos dan berfungsi untuk mengungkapkan dan memberi pembenaran bagi nilai-nilai dominan yang berlalu dalam suatu periode tertentu. Adapun makna-makna konotasi tersebut telah menguasai masyarakat. Makna konotasi tersebut telah menebal menjadi mitos, sehingga dapat diungkapkan bahwa pesan dalam kampanye Iklan Politik Caleg Superman tahun 2014 dalam website www.egymassadiah.info, merupakan sebuah kode atau peringatan awal bagi masyarakat agar berhati-hati dalam memberikan surat suaranya kepada si Caleg itu sendiri. Dalam mitos persuasif, masyarakat didorong untuk memberikan suaranya melalui nilai-nilai kepahlawanan yang ditampilkan dalam APK (Alat Peraga Kampanye) tersebut.

3. Dalam Iklan Politik Caleg Superman tahun 2014 pada website www.egymassadiah.info, ideologi sosial yang sudah mendarah daging di masyarakat Indonesia susah untuk dihilangkan. Karena masyarakat menilai bahwa yang berpostur gagah dan berwajah tampan itu mempunyai cikal-bakal menjadi seorang pemimpin, maka para calon-calon penguasa Negara juga semakin mendistorsi realitas dengan menciptakan iklan iklan persuasif yang berlebihan, guna kepentingan dirinya dalam mencapai target suara agar terpilih sebagai anggota Legislatif dalam pemilu.

\section{DAFTAR PUSTAKA}

a. Buku

[1] Barthes, Roland. (1994), Elements of Semiology atau Elemen-elemen Semiologi, terjemahan Kahfie Nazarudin. (2012), Jalasutra, Yogyakarta.

[2] Hutcheon, Linda. (2002), The Politics of Posmodernism atau Politik Posmodernisme, terjemahan Apri Danarto. (2004), Jendela, Yogyakarta.

[3] Sobur, Alex. (2009), Semiotika komunikasi, PT Remaja Rosdakarya, Bandung.

[4] Tinarbuko, Sumbo. (2009), Iklan Politik Dalam Realitas Media, Jalasutra, Yogyakarta.

b. Laman

http://egymassadiah.info (diunduh pada: 10/01/2015).

http://sumbotinarbuko.com (diunduh pada: 16/01/2015).

http://dgi-indonesia.com (diunduh pada: 17/03/2015). 